\title{
Morphine Dependence With or Without Tolerance in Formalin-Treated Mice: Further Evidence for the Dissociation
}

\author{
A.F.M. Mohibur Rahman, Masakatsu Takahashi and Hiroshi Kaneto \\ Department of Pharmacology, Faculty of Pharmaceutical Sciences, Nagasaki University, 1-14, Bunkyo-machi, Nagasaki 852, Japan
}

Received July 4, $1994 \quad$ Accepted August 29, 1994

\begin{abstract}
Pain associated-anxiety induced by formalin, which resulted in a significant delay in the development of tolerance to morphine antinociception, failed to prevent the development of physical dependence as evidenced by naloxone challenge. Dependence also developed in mice rendered tolerant to morphine. Thus, the development of morphine dependence was observed in the absence and presence of tolerance to morphine antinociception; Our results further confirm the dissociation of opioid tolerance and dependence in the animal model of experimental pain/anxiety.
\end{abstract}

Keywords: Tolerance, Dependence, Morphine

A series of experiments performed in our laboratory showed that morphine analgesia, the development of tolerance and dependence are separable from each other $(1,2)$. Such possible dissociation of tolerance and dependence was also demonstrated (3-5). Meanwhile, in most studies, tolerance and dependence consistently occurred together, and the parallel appearance of both phenomena infered the existence of a common mechanism $(6,7)$. So far most of the experiments have been conducted in normal healthy animals; and indeed, as far as we know, there have been few reports on the observation of dependence in the pain-suffering animal $(8,9)$. Inasmuch as we have recently reported that a significant delay was observed in the development of morphine tolerance in the presence of formalin pain, on the controversial problem of whether pain can prevent the development of morphine tolerance (10), we examined whether the dependence on morphine develops in mice suffering from pain.

Male mice of the ddY strain, weighing 18 to $20 \mathrm{~g}$, were housed in a room maintained at $22^{\circ} \mathrm{C}$. They were given normal laboratory diet ad libitum. After reaching $25 \mathrm{~g}$, they were used in the experiment. Morphine $\mathrm{HCl}$ (Takeda, Osaka), naloxone $\mathrm{HCl}$ (Sigma, St. Louis, MO, USA) and formalin (Nacalai Tesque, Kyoto) were dissolved in saline and given s.c. or i.p. Three different groups of mice were treated with $20 \mu l$ of $2 \%$ formalin into the dorsal part of the left hind paw on the 1st day. To intensify or prolong pain during the experimental period, two of the groups received an additional formalin injection into the right hind paw on the 3 rd day or on the 5 th day, respectively. The control group was treated with saline instead of formalin. The pain threshold was measured with a slight modification of the method of Randall and Selitto (11) using an analgesy-meter (MK-300; Muromachi, Tokyo). Daily injection of morphine at $10 \mathrm{mg} / \mathrm{kg}$, s.c. was started $2 \mathrm{hr}$ after the formalin or saline injection on the 1st day, and the antinociceptive effect was measured by the tail-pinch method (12). A significant reduction in the antinociceptive effect was an indication of tolerance. With the same schedule as used for formalin and morphine treatment, mice were challenged with naloxone at 1 $\mathrm{mg} / \mathrm{kg}$, i.p. $1 \mathrm{hr}$ after the scheduled dose of morphine on the 5 th day or on the 9 th day. Withdrawal signs were observed for $10 \mathrm{~min}$ after naloxone injection. Mice were kept on a stool during observation, and withdrawal signs, such as peeping below, rearing, falling, jumping, circling and backward locomotion, were counted (5). The results are expressed as the mean \pm S.E. Differences between the individual mean values in different groups are analyzed by Dunnett's test.

Daily injection of morphine resulted in the development of tolerance to morphine antinociception in the saline-treated group, but the development of morphine tolerance was significantly delayed in the formalin-treated mice until the 6th day, and then a gradual reduction of the antinociceptive effect led to the complete development of tolerance by 7 or 8 days, as evidenced by no substantial antinociception. An additional injection of formalin on 

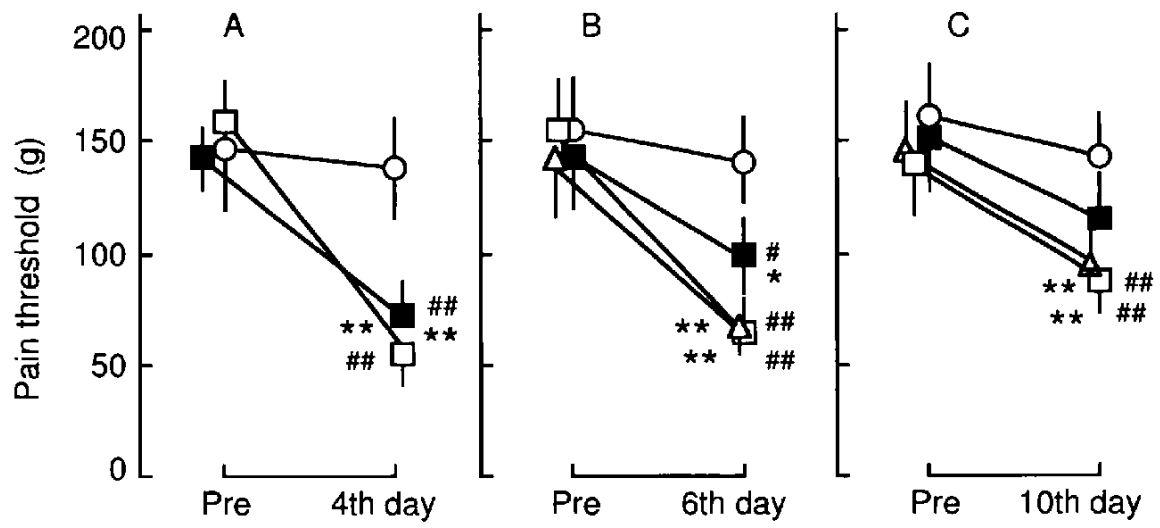

Fig. 1. Changes of the pain threshold by an additional formalin injection. Mice received $20 \mu 1$ of formalin (2\%) into the left hind paw on the lst day and the right hind paw on the 3rd day $(\square)$ or on the 5 th day $(\triangle)$. The pain threshold was measured at the left hind paw before the formalin treatment (Pre) and on the 4th day (A), the 6th day (B) or the 10th day (C). The saline control group received saline instead of formalin $(\bigcirc)$, and the formalin control group received only the initial formalin $(\square)$. In mice treated twice with formalin, the pain threshold measured at the right hind paw on these test days was the same as that of the left one (to avoid complexity, data omitted from this figure). Each point indicates the mean \pm S.E. ( $n=8-16)$. Significantly different from the corresponding value on the 1st day (Pre), ${ }^{*} \mathrm{P}<0.05,{ }^{* *} \mathrm{P}<0.01$. Significantly different from the control group on the corresponding days, ${ }^{\prime \prime} \mathrm{P}<0.05,{ }^{\# \prime} \mathrm{P}<0.01$.

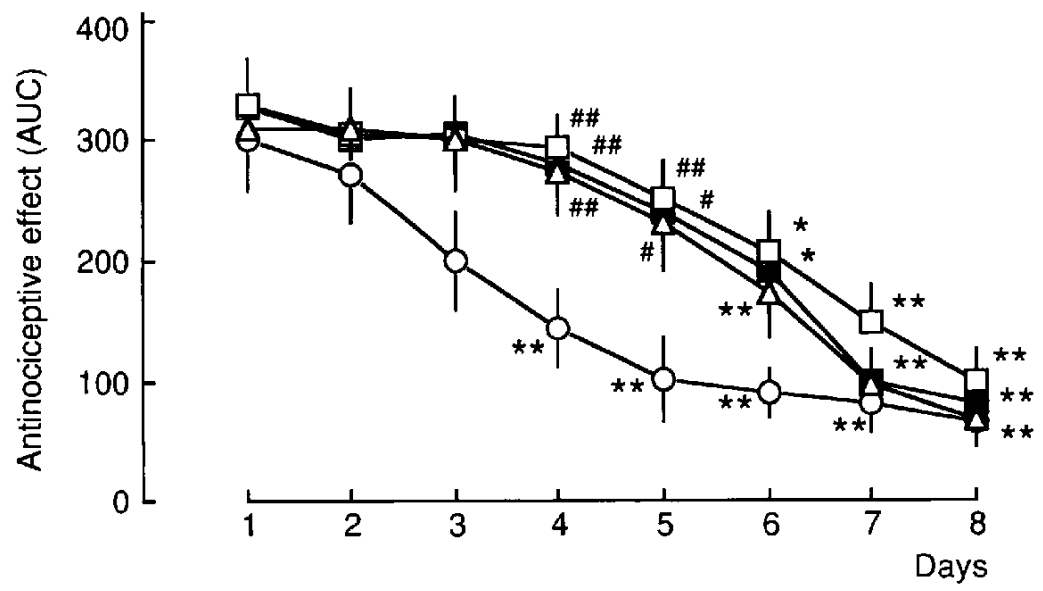

Fig. 2. Development of tolerance to morphine antinociception in the formalin treated mice. Mice were divided into 3 groups and received daily morphine, $10 \mathrm{mg} / \mathrm{kg}$, s.c.; and $20 \mu \mathrm{l}$ of formalin (2\%) was given into the left hind paw on the 1 st day. Two of the groups received an additional formalin injection into the right hind paw on the 3rd day $(\square)$ or on the 5th day $(\triangle)$ ). The other group received no additional formalin injection $(\square)$. The control group $(\bigcup)$ received daily morphine but was given saline instead of formalin on the $1 \mathrm{st}$ day. Each point indicates the mean \pm S.E. $(\mathrm{n}=8)$. Significantly different from the corresponding value on the 1st day, ${ }^{*} \mathrm{P}<0.05,{ }^{* *} \mathrm{P}<0.01$. Significantly different from the effect in the control group on the corresponding days, ${ }^{4} \mathrm{P}<0.05,{ }^{\text {*t }} \mathrm{P}<0.01$.

the 3rd day or on the 5th day that produced pain in both hind paws (Fig. 1) had no effect on the delay in the development of morphine tolerance (Fig. 2).

Almost equipotent physical dependence, and likely to be maximum in this administration schedule, developed in control groups treated with morphine alone for 5 days and for 9 days, as evidenced by the appearance of withdrawal signs following naloxone challenge; likewise, withdrawal signs in the group given a single formalin treat- ment in the absence (the 5th day) or the presence (the 9th day) of tolerance development were observed to the same extent as in the control group (Fig. 3). The magnitude of withdrawal signs among the formalin-treated groups was nearly equivalent to that of the morphine control group.

We have demonstrated that a single injection of formalin produces tonic pain lasting around one week and causes a significant delay in the development of morphine tolerance (10), and that such delay is attributable to pain- 

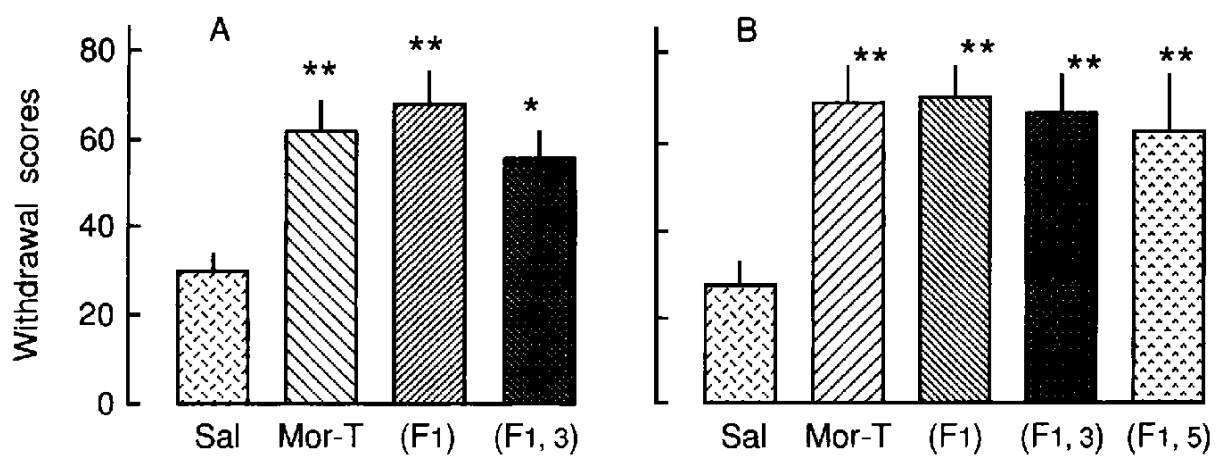

Fig. 3. Development of physical dependence on morphine in the presence or absence of morphine tolerance. Mice received daily morphine $\left(10 \mathrm{mg} / \mathrm{kg}\right.$, s.c.) and formalin on the 1 st day $\left(F_{1}: \square\right.$ in Figs. 1 and 2$)$, the 1 st and 3 rd day $\left(F_{1,3}: \square\right.$ in Figs. 1 and 2$)$ or the 1st and 5th day $\left(\mathrm{F}_{1,5}: \wedge\right.$ in Figs. 1 and 2$)$. The morphine tolerant (Mor-T: $O$ in Figs. 1 and 2$)$ group received saline instead of formalin; and the saline control (Sal) received saline instead of daily morphine and formalin. Naloxone at $1 \mathrm{mg} / \mathrm{kg}$, i.p. was given $1 \mathrm{hr}$ after the schedule dose of morphine in all groups, including the saline-treated control group, on the 5th day (A: absence of tolerance development) or on the 9th day (B: presence of tolerance development). To avoid an adaptation to the test procedure, different groups in A and B were used. Each column indicates the mean \pm S.E. $(n=15-32)$. Significantly different from the saline treated control group, ${ }^{*} \mathrm{P}<0.05,{ }^{* *} \mathrm{P}<0.01$.

associated anxiety rather than or, to a lesser extent, pain itself (13). In this experiment, we injected formalin twice into the animal at different time intervals in both hind paws and confirmed that such treatment induced rather intensified pain in both sides; however, these additional injections of formalin did not influence the delay in the development of morphine tolerance. In spite of our assumption that intensification of pain by a formalin booster might sustain the delay in the development of morphine tolerance and subsequently affect the dependence development, such intensified pain failed to prevent either the development of morphine tolerance or dependence. Our previous report that the adrenergic blockers phentolamine and propranolol, completely suppressing the development of morphine tolerance, failed to prevent the development of dependence in mice (5) agrees with the present results that in the absence of tolerance, dependence developed to the same extent as in the animals treated with morphine alone. There are some reports indicating that the development of tolerance to as well as dependence on opioids are rare in patients suffering from chronic pain $(14,15)$, and that neither morphine tolerance developed (10) nor some kind of withdrawal signs, i.e., teeth chattering and diarrhea, remarkably appeared in formalin-treated rats (8). These differences from our present work may be due to the species, schedule and methods of observations. In conclusion, it can be seen that dependence on morphine develops in the absence and presence of morphine tolerance; and therefore, our results provide evidence that mechanisms underlying the development of opioid tolerance and dependence are mutually different and dissociable in such an animal model of experimental pain/anxiety.

\section{REFERENCES}

1 Kaneto H, Hirota N and Yamazaki A: Possible dissociation of morphine analgesia from its tolerance liability in mice. Life Sci 33, 353-356 (1983)

2 Kaneto H, Yamazaki A and Kihara T: Evidence for the dissociation of morphine analgesia, tolerance and dependence. J Pharm Pharmacol 37, $507-508$ (1985)

3 Johnson SM and Duggan AW: Dependence in the absence of tolerance to morphine. Eur J Pharmacol 97, 305-308 (1984)

4 Panerai AE, Rovati LC, Cocco E, Sacerdote $P$ and Mantegazza $P$ : Dissociation of tolerance and dependence to morphine: a possible role for cholecystokinin. Brain Res 410, 52-60 (1987)

5 Ohta $\mathrm{A}$ and Kaneto H: Development of physical dependence on morphine not accompanied with tolerance formation. J Pharmacobiodyn 15, 443-447 (1992)

6 Wunster M, Schulz R and Herz A: Opioid tolerance and dependence: Reevaluating the unitary hypothesis. Trends Pharmacol Sci 12, 64-67 (1985)

7 Sharma S, Klee WA and Nirenberg M: Dual regulation of adenylate cyclase accounts for narcotic dependence and tolerance. Proc Natl Acad Sci USA 72, 3092-3096 (1965)

8 Vaccarino AL and Couret LC $\mathrm{J}_{\mathrm{r}}$ : Formalin induced pain antagonizes the development of opiate dependence in the rat. Neurosci Lett 161, 195-198 (1993)

9 Vaccarino AL, Marek P, Kest B, Ben-Eliyahu S, Couret LC Jr, Kao B and Liebeskind JC: Morphine fails to produce tolerance when administered in the presence of formalin pain in rats. Brain Res 627, 287-290 (1993)

10 Rahman AFMM, Takahashi $\mathrm{M}$ and Kaneto $\mathrm{H}$ : Development of tolerance to morphine antinociception in mice treated with nociceptive stimulants. Jpn J Pharmacol 63, 59-64 (1993)

11 Randall LO and Selitto JJ: Method for measurement of analgesic activity on inflamed tissue. Arch Int Pharmacodyn Ther 111, $409-419$ (1957)

12 Takagi $H$, Inukai $T$ and Nakama $M$ : A modification of Haffner's method for testing analgesics. Jpn J Pharmacol 16, 


\section{$287-294$ (1966)}

13 Rahman AFMM, Takahashi $\mathbf{M}$ and Kaneto $\mathbf{H}$ : Involvement of pain associated anxiety in the development of morphine tolerance in formalin treated mice. Jpn J Pharmacol 65, 313-317 (1994)

14 Melzack R: Human versus pain. The dilemma of morphine. In
Advances in Pain Research and Therapy, Edited by Secuteri F, Terenius L, Vecchiet L, Maggi CA, Nicolodi M and Alessandri M, Vol 20, pp 149-159, Ravan Press, New York (1992)

15 Kanner RM and Foley KM: Patterns of narcotic drug use in cancer pain clinic. Ann NY Acad Sci 362, 162-172 (1981) 